Supplement of Clim. Past, 11, 253-263, 2015

http://www.clim-past.net/11/253/2015/

doi:10.5194/cp-11-253-2015-supplement

(C) Author(s) 2015. CC Attribution 3.0 License.

(c) (i)

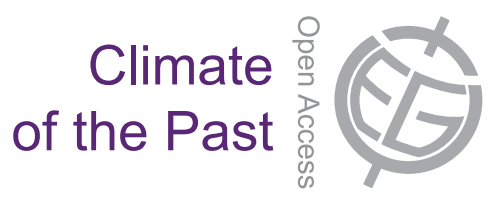

Supplement of

\title{
A comparison of model simulations of Asian mega-droughts during the past millennium with proxy reconstructions
}

B. Fallah and U. Cubasch

Correspondence to: B. Fallah (bijanf@zedat.fu-berlin.de) 


\begin{tabular}{lcccc}
\hline MCA1 of & Niño 3.4 & Niño $1+2$ & Niño 4 & NHT \\
\hline SST of mil0010 & 0.68 & 0.39 & 0.71 & 0.49 \\
PDSI of mil0010 & 0.24 & NS & 0.22 & 0.14 \\
SST of mil0012 & 0.63 & 0.39 & 0.63 & 0.33 \\
PDSI of mil0012 & 0.21 & NS & 0.20 & NS \\
SST of mil0013 & 0.70 & 0.54 & 0.69 & 0.43 \\
PDSI of mil0013 & 0.19 & NS & 0.25 & NS \\
SST of mil0014 & 0.28 & 0.25 & 0.30 & 0.15 \\
PDSI of mil0014 & NS & 0.13 & NS & NS \\
SST of mil0015 & 0.61 & 0.57 & 0.64 & 0.41 \\
PDSI of mil0015 & NS & 0.14 & 0.13 & -0.21 \\
SST of r1i1p121 & 0.49 & 0.51 & 0.55 & 0.25 \\
PDSI of r1i1p121 & 0.28 & 0.35 & 0.33 & NS \\
SST of r1i1p124 & 0.45 & 0.41 & 0.53 & 0.22 \\
PDSI of r1i1p124 & 0.36 & 0.38 & 0.34 & 0.12 \\
\hline
\end{tabular}

Table 1: Correlations of MCA timeseries and climate indices. All the coefficients are significant with $p-$ value $<0.01$. NS stands for Not Significant. 


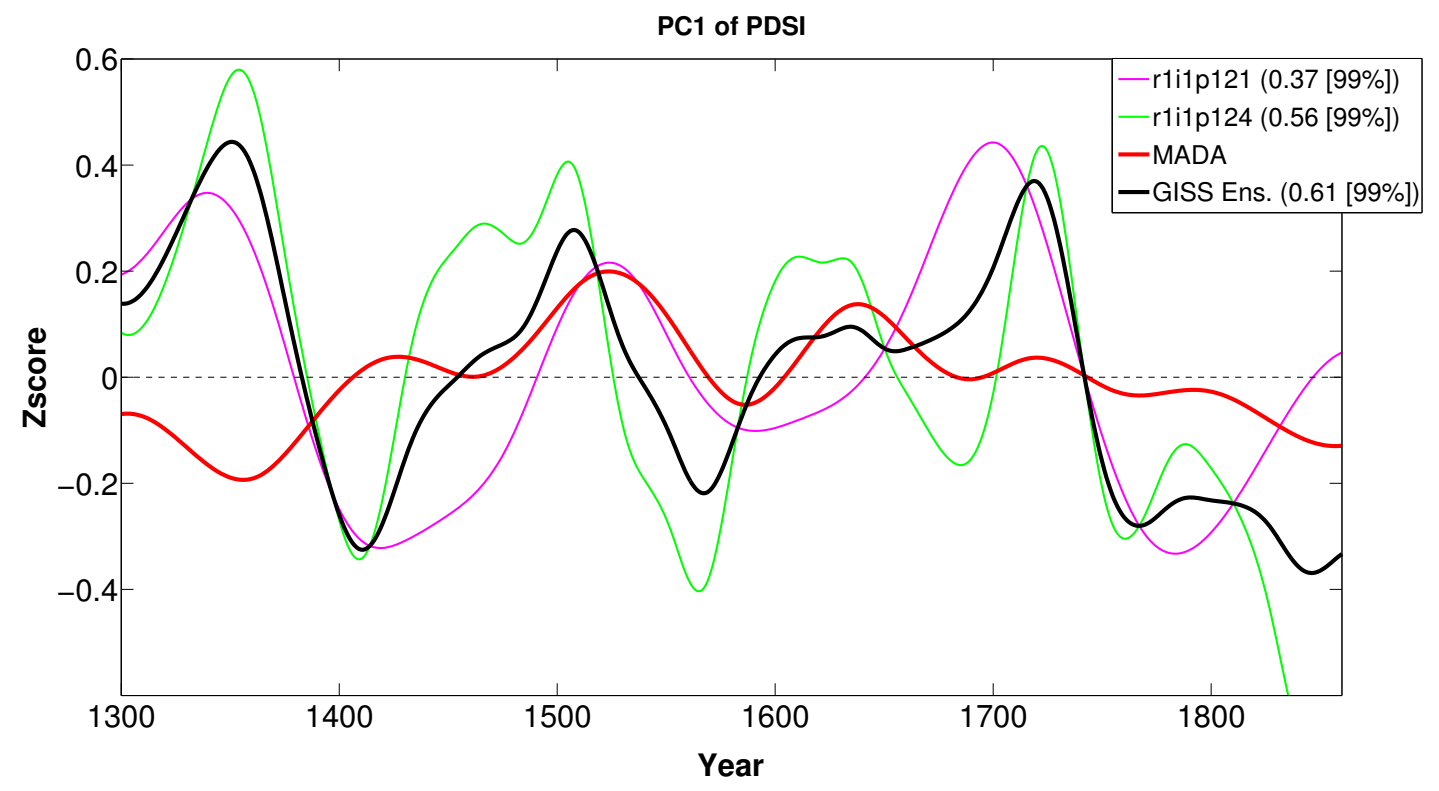

Figure 1: (S.1) Smoothed PC1 trends of PDSI for GISS and MADA. The numbers in parenthesis are correlation coefficients. Black solid line is the ensemble average.

a) Regime 1

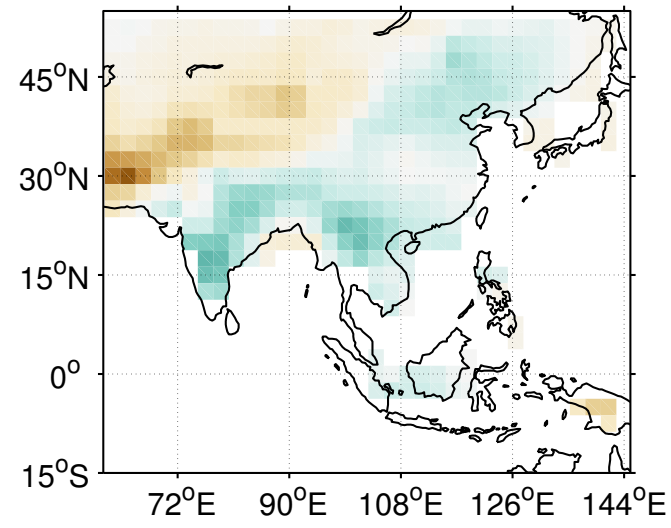

b) Regime 2

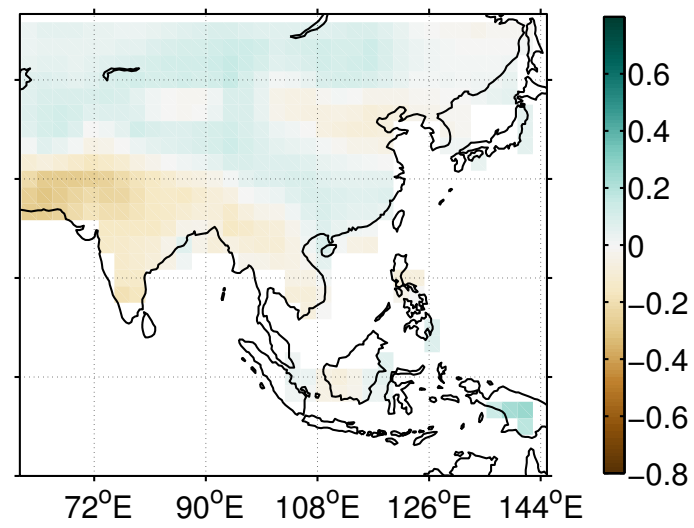

Figure 2: (S.5) PDSI composites for the two regimes from ECHAM5/MPIOM. 
a) Regime 1

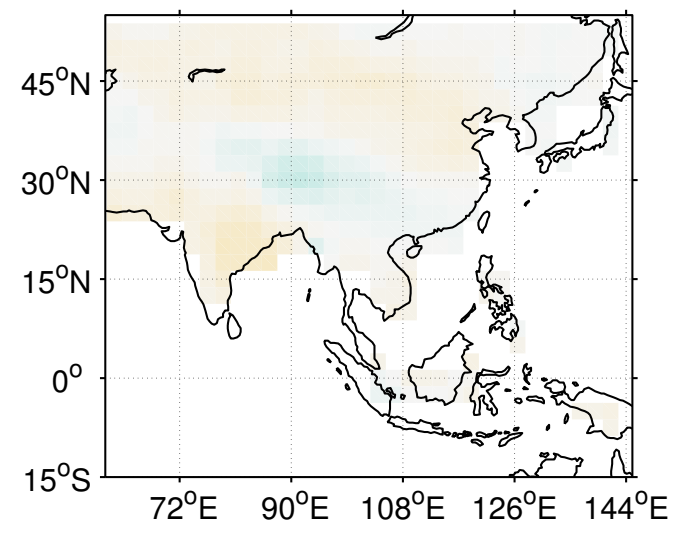

b) Regime 2

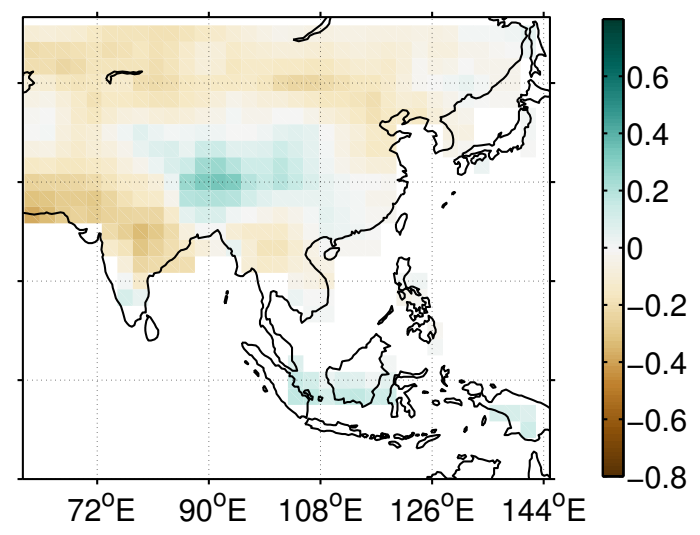

Figure 3: (S.6) PDSI composites for the two regimes from GISS-E2-R. 